\title{
ANALISIS TINGKAT KEBISINGAN DAN UPAYA PENGENDALIAN PENYAKIT AKIBAT KERJA DI AREA MINING PT. XYZ, SUMBAWA BARAT, NUSA TENGGARA BARAT
}

\author{
Haryandi*, Veni Rori Setiawati** \\ *Fakultas Teknologi Pertanian, Universitas Teknologi Sumbawa \\ email: veni.rori@uts.ac.id \\ **P Pusat Studi Terapan K3 dan Lingkungan, Universitas Teknologi Sumbawa \\ email: $\underline{\text { haryandi@uts.ac.id }}$
}

\begin{abstract}
ABSTRAK
Aspek K3 berorientasi menciptakan lingkungan kerja yang aman, nyaman, dan sehat bagi pekerja. Industri pertambangan memiliki tingkat resiko cukup tinggi khususnya terkait kebisingan di tempat kerja yang berasal dari intensitas suara tinggi pada aktivitas penambangan, peledakan, alat, mesin, dan perbengkelan. Penelitian dilakukan di area penambangan PT. XYZ, salah satu perusahaan tambang terbuka yang berlokasi di Sumbawa Barat, Nusa Tenggara Barat dengan pengukuran kebisingan dilakukan dengan metode personal sampling dilakukan menggunakan peralatan Edge 5, dan mengetahui upaya pengendalian kebisingan dengan cara observasi dan wawancara mendalam dengan metode deskriptif kualitatif. Hasil penelitian didapatkan pembagian 12 Similar Exposure Group (SEG) di area mining PT.XYZ dengan hasil pengukuran kebisingan personal menunjukkan rentang 81.1-87 dB dengan SEG tertinggi di area Mine Batch Plant dan terendah di SEG Mine Drill Sampler. PT. XYZ telah melakukan upaya pengendalian kebisingan dengan prinsip hirarki kontrol yaitu eliminasi, substitusi, rekayasa teknik, administrasi, dan alat pelindung diri.
\end{abstract}

Keywords: Kebisingan, K3, Mining, Similar Exposure Group, Hirarki Kontrol

\begin{abstract}
Occupational Health and Safety aspects create a safe and healthy work environment for workers. The mining industry has a high level of risk, especially related to workplaces originating from high noise intensity in mining, explosions, tools, and machinery and workshop activities. The research was conducted in the mining area of PT. XYZ, a company located in West Sumbawa, West Nusa Tenggara Province, was carried out using a private sampling method using Edge 5 equipment, and knowing control efforts by observation and in-depth qualitative descriptive methods. The results showed that there were 12 Similar
\end{abstract}


Exposure Groups (SEG) in the mining area of PT. XYZ. Personal noise dosimetry measurement results showing a range of 81.1-87 dB with the highest SEG in the Mine Batch Plant area and the lowest in the SEG Mine Drill Sampler. PT. XYZ has carried out control efforts with the principles of the control hierarchy, namely elimination, substitution, engineering, administration, and personal protective equipment.

Keywords: Noise, OHS, Mining, Similar Exposure Groups, Hierarchy Control

\section{PENDAHULUAN}

Upaya pengelolaan Keselamatan dan kesehatan kerja (K3) dilakukan guna menciptakan lingkungan kerja yang aman, nyaman, dan sehat bagi pekerja. Pengelolaan K3 yang baik menjadi aspek penting khususnya di industri pertambangan dimana sifat pertambangan yang padat teknologi, padat karya, padat modal, dan resiko yang dinamis. Regulasi terkait K3 dikeluarkan pemerintah guna meningkatkan kualitas penerapan K3 di Pertambangan guna mencegah kecelakaan dan penyakit akibat kerja (PAK). Regulasi terbaru diantaranya PerMen ESDM No. 26 Tahun 2018 tentang Pelaksanaan Kaidah Pertambangan yang Baik dan Pengawasan Pertambangan Mineral dan Batubara, KepMen ESDM No. 1827.K/30/MEM/2018 tentang Pedoman Pelaksanaan Kaidah Teknik Pertambangan yang Baik, Permenaker No. 5 tahun 2018 Keselamatan dan Kesehatan Lingkungan Kerja, dan Kepdirjen Minerba No.185.K/37.04/DJB/2019 tentang
Petunjuk Teknis Pelaksanaan Keselamatan Pertambangan dan Pelaksanaan, Penilaian dan Pelaporan Sistem Manajemen Keselamatan Pertambangan Mineral dan Batubara (ESDM， 2018; Kemenaker, 2018; Keputusan Dirjen Minerba, 2019).

Salah satu aspek K3 di pertambangan yang diatur terkait pengelolaan K3 lingkungan kerja. Definisi pengelolaan lingkungan kerja menurut Permenaker No.5 yaitu aspek higiene di tempat kerja yang di dalamnya mencakup faktor fisika, kimia, biologi, ergonomi dan psikologi yang keberadaannya di tempat kerja dapat mempengaruhi keselamatan dan kesehatan tenaga Kerja. Aspek lingkungan kerja yang diatur mencakup debu, getaran, pencahayaan, kebisingan, udara kerja, radiasi, iklim kerja, faktor biologi, faktor kimia, dan kebersihan lingkungan. Kebisingan di pertambangan berasal dari aktivitas mesin, peledakan, kendaraan, dan perbengkelan. Dalam Permenaker No.5 Tahun 2018, definisi kebisingan adalah bunyi yang tidak diinginkan dari suatu usaha atau kegiatan 
dalam tingkat dan waktu yang dapat menimbulkan gangguan kesehatan manusia dan kenyamanan (Kemenaker, 2018). Dampak yang ditimbulkan dari kebisingan diantaranya gangguan komunikasi atau tuli, gangguan fisiologis, dan gangguan psikologis jika paparan di lokasi kerja lebih tinggi dari Nilai Ambang Batas (NAB) yang ditetapkan (Hadzi-Nikolova, Mirakovski and Doneva, 2016).

Tabel 1. Nilai Ambang Batas Kebisingan Menurut Permenaker No.5 Tahun 2018

\begin{tabular}{|c|c|c|}
\hline \multicolumn{2}{|c|}{$\begin{array}{c}\text { Waktu pemajanan } \\
\text { perhari }\end{array}$} & \multirow{2}{*}{$\begin{array}{c}\text { Intensitas } \\
\text { kebisingan } \\
\text { dalam dB }\end{array}$} \\
\hline 8 & \multirow{4}{*}{ Jam } & \\
\hline 4 & & 88 \\
\hline 2 & & 91 \\
\hline 1 & & 94 \\
\hline 30 & \multirow{6}{*}{ Menit } & 97 \\
\hline 15 & & 100 \\
\hline 7,5 & & 103 \\
\hline 3,75 & & 106 \\
\hline 1,88 & & 109 \\
\hline 0,94 & & 112 \\
\hline 28,12 & \multirow{6}{*}{ Detik } & 115 \\
\hline 14,06 & & 118 \\
\hline 7,03 & & 121 \\
\hline 3.52 & & 124 \\
\hline 1,76 & & 127 \\
\hline 0,88 & & 130 \\
\hline
\end{tabular}

\begin{tabular}{|l|l|}
\hline 0,44 & 133 \\
\hline 0,22 & 136 \\
\hline 0,11 & 139 \\
& \\
& \\
\hline
\end{tabular}

Catatan: Tidak boleh terpajan lebih dari $140 \mathrm{dBa}$, walau sesaat.

Pengelolaan kebisingan adalah salah satu aspek penting dalam pengelolaan lingkungan kerja di pertambangan dikarenakan tempat kerja memiliki sumber bahaya kebisingan diatas ambang batas dari operasi peralatan kerja yang dapat menimbulkan gangguan pendengaran (Octavia, Asnawati and Yasmina, 2013) (Beamer, 2016). Pengaruh paparan kebisingan secara umum tergantung tinggi rendahnya intensitas kebisingan dan lamanya waktu pemaparan. Pengaruh kebisingan intensitas tinggi (di atas NAB) di usaha pertambangan menyebabkan kerusakan pada telinga yang dapat menurunkan kualitas pendengaran baik yang bersifat sementara maupun permanen dari mesin dan alat angkat angkut tambang (Utami, Nirmala and Meilasari, 2020). Secara fisiologis, kebisingan dengan intensitas tinggi menyebabkan gangguan kesehatan diantaranya peningkatan tekanan darah ( $\pm 10 \mathrm{mmHg})$, peningkatan denyut nadi, risiko serangan jantung, gangguan sensoris, konstriksi pembuluh darah perifer pada tangan dan kaki, gangguan keseimbangan organ dan gangguan 
pencernaan (Amir et al., 2019). Selain efek kesehatan, kebisingan juga berdampak kepada kegiatan operasional yang dapat menyebabkan reaksi masyarakat yang dapat memprotes kegiatan pertambangan akibat kebisingan yang diakibatkan oleh alat dan aktivitas pertambangan (Mayasari and Khairunnisa, no date). Hasil penelitian Utami, et.al pada pertambangan batuan menggunakan crusher menyatakan adanya hubungan korelasi variabel karakteristik riwayat sakit telinga dengan keluhan pendengaran yang dialami oleh pekerja (Utami, Nirmala and Meilasari, 2020). Nilai paparan kebisingan berpotensi menyebabkan gangguan pendengaran kepada pekerja dalam jangka panjang (Mcbride, 2004).

Hasil identifikasi awal., intensitas kebisingan di area tambang PT. XYZ berkisar pada 82-85 dB yang bersumber dari aktivitas kerja, peledakan, mesin, dan kendaraan angkat angkut. Penelitian ini dilakukan untuk mengetahui upaya pengendalian kebisingan di PT. XYZ yang berperan dalam upaya memastikan pekerja terhindar dari resiko penyakit akibat kerja. Selain itu, dengan mengetahui kondisi kebisingan di perusahaan menjadi upaya perusahaan menjalankan regulasi pemerintah yang terkait dengan K3 dan kewajiban memastikan kondisi pekerjaan aman dan sehat bagi pekerja.
Metode pengukuran kebisingan di tempat kerja dibagi menjadi 2 tipe yaitu personal sampling dan area sampling. Personal sampling dilakukan dengan cara mengukur paparan pekerja secara personal menggunakan noise dosimeter selama beraktivitas dengan minimal jangka waktu pengukurn $75 \%$ dari total waktu kerja harian. Sedangkan area sampling dilakukan dengan mengukur paparan area kerja, alat, atau mesin dengan menggunakan Sound Level Meter (SLM) untuk mendapatkan intensitas kebisingan di lokasi kerja atau peralatan. Dalam hal paparan personal pekerja, tahapan awal yang dilakukan adalah mengelompokkan pekerja sesuai grup paparan atau Similar Exposure Group (SEG) melalui asesmen awal apakah kelompok tertentu dengan aktivitas tertentu memeliki paparan yang sama.

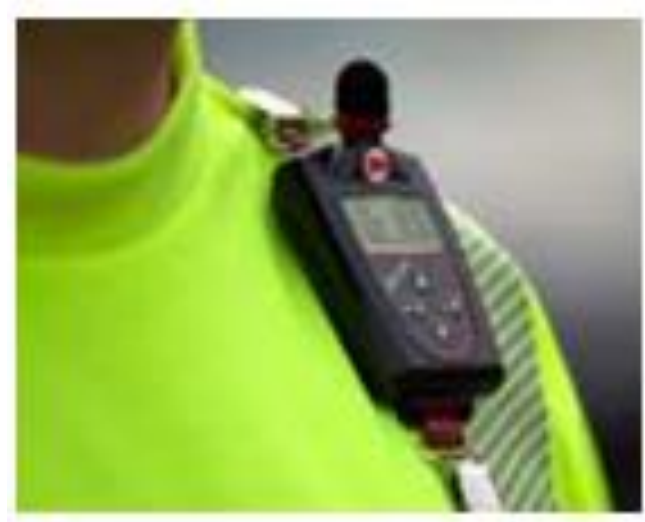

Gambar 1. Alat Pengukuran Kebisingan Personal

Penelitian dilakukan dengan mengukur paparan kebisingan pekerja menggunakan peralatan noise dosimeter 
Edge 5 terkalibrasi, observasi lapangan, dan wawancara kepada pihak berkepentingan dengan metode deskriptif kualitatif. Lokasi penelitian ini dilakukan di area mining atau penambangan PT. XYZ yang bergerak di tambang terbuka berlokasi di Pulau Sumbawa, Nusa Tenggara Barat. Proses penambangan dilakukan 24 jam dengan kapasitas produksi sekitar 120.000 ton per hari dimulai dari proses peledakan, loading unloading dengan alat shovel kemudian diangkut dengan haul truck tipe Catterpillar 793C berkapasitas 250 ton satu kali angkut,selanjutnya batuan diproses dalam primary crusher dan overland conveyor untuk memecahkan batuan menjadi ukuran lebih kecil. Batuan ukuran kecil didistribusikan untuk masuk ke dalam pabrik pengolahan untuk digerus menggunakan grinding menjadi ukuran yang cukup kecil agar dapat diproses di area flotasi untuk melepas partikel mineral tembaga dan emas dari gangue atau host rock. Produk berupa konsentrat dipompa ke filter plant yang terletak di area port untuk dikurangi kadar air sebelum didistribusikan ke konsumen menggunakan kapal (Fitriana, 2009). Alat angkut, mesin perbengkelan, dan peledakan berpotensi menimbulkan kebisingan yang dapat berdampak negatif kepada para pekerja (Haryandi, Setiawati and Mayasisca, 2020).

\section{METODE PENELITIAN}

Metode penelitian dilakukan dengan observasional analitik yang berlokasi di area penambangan PT. XYZ dengan mengelompokkan area sesuai paparan menurut kriteria Similar Exposure Group (SEG). Desain penelitian menggunakan cross sectionalstudy dengan populasi pada penelitian ini sejumlah 12 SEG dengan responden masing-masing 6 orang tiap SEG. Metode pengukuran kebisingan dilakukan dengan metode personal sampling dilakukan menggunakan peralatan Edge 5 yang mengukur rentang suara $70 \mathrm{~dB}$ hingga $140 \mathrm{~dB}$, alat ini telah sesuai dengan standar ANSI S1.25 dan IEC61252 tipe 2 (Bonnet et al., 2019).

Variabel pada penelitian ini meliputi intensitas kebisingan, ambang pendengaran dan karakteristik pekerjaan (jenis aktivitas kerja, sumber paparan kebisingan, lama pajanan per hari). Pengukuran dilakukan disaat jam kerja atau saat alat atau mesin bekerja sehingga pengukuran lebih akurat karena terjadi proses kerja yang semestinya. Dalam hal upaya pengendalian kebisingan, peneliti melakukan observasi dan wawancara mendalam dengan metode deskriptif kualitatif dengan melibatkan informan utama petugas K3 lingkungan kerja PT. $\mathrm{XYZ}$, supervisor industrial hygiene, dokter perusahaan, dan supervior mining. Dari hasil wawancara terhadap informan 
secara mendalam kemudian dilakukan observasi lapangan untuk mengkonfirmasi hasil observasi dengan wawancara.

\section{HASIL DAN PEMBAHASAN}

Penentuan Similar Exposure Group (SEG)

Pengelompokan group paparan atau Similar Exposure Group (SEG) dilakukan dengan observasi dan pengambilan sampel terhadap sekelompok karyawan yang memiliki profil paparan umum yang sama karena kesamaan frekuensi tugas yang mereka lakukan, bahan/agen dan proses yang digunakan serta cara mereka melakukan tugasnya. Data sampel diperlukan, baik data historis atau data yang dikumpulkan untuk tujuan menentukan SEG, untuk mendukung data pengamatan misalnya tingkat kebisingan, tingkat debu yang terhirup dan paparan zat berbahaya dan lain-lain. Setelah data yang dikumpulkan memadai, analisis statistik juga dapat dilakukan untuk mengonfirmasi bahwa grup tersebut mewakili SEG. Adapun SEG yang telah ditetapkan di PT.XYZ di area mining beserta aktivitas, sumber kebisingan, jam kerja, dan NAB sesuai peraturan pemerintah adalah sebagai berikut :

Tabel 2. Pembagian Similar Exposure Group (SEG) Area Mining, PT. XYZ

\begin{tabular}{|c|c|c|c|c|}
\hline SEG & Aktivitas Kerja & $\begin{array}{c}\text { Sumber } \\
\text { Kebisingan }\end{array}$ & $\begin{array}{c}\text { Jam } \\
\text { Kerja }\end{array}$ & NAB \\
\hline $\begin{array}{l}\text { Mine } \\
\text { Batchplant }\end{array}$ & $\begin{array}{l}\text { Peremukan batuan dan } \\
\text { pencampuran untuk beton, } \\
\text { maintenance alat }\end{array}$ & $\begin{array}{l}\text { Alat Crusher, Belt } \\
\text { Conveyor, Alat } \\
\text { muat }\end{array}$ & 12 & 83.3 \\
\hline $\begin{array}{l}\text { Mine Blast } \\
\text { Crew }\end{array}$ & $\begin{array}{l}\text { Persiapan peledakan, } \\
\text { peledakan, pembersihan area }\end{array}$ & $\begin{array}{l}\text { Aktivitas } \\
\text { penambangan, } \\
\text { peledakan, mesin } \\
\text { drilling }\end{array}$ & 12 & 83.3 \\
\hline $\begin{array}{l}\text { Mine Blast } \\
\text { Drillers }\end{array}$ & $\begin{array}{l}\text { Operator mesin drill, } \\
\text { persiapan peledakan }\end{array}$ & $\begin{array}{l}\text { Aktivitas } \\
\text { penambangan, } \\
\text { peledakan, mesin } \\
\text { drilling }\end{array}$ & 12 & 83.3 \\
\hline $\begin{array}{l}\text { Mine Drill } \\
\text { Sampler }\end{array}$ & $\begin{array}{l}\text { Pengambilan sampel batuan } \\
\text { hasil drilling, persiapan } \\
\text { peledakan }\end{array}$ & $\begin{array}{l}\text { Peledakan, mesin } \\
\text { drilling, Aktivitas } \\
\text { penambangan }\end{array}$ & 12 & 83.3 \\
\hline
\end{tabular}




\begin{tabular}{|c|c|c|c|c|}
\hline $\begin{array}{l}\text { Mine HT } \\
\text { Operator }\end{array}$ & Operator Haul Truck 793 & $\begin{array}{l}\text { Aktivitas } \\
\text { penambangan, } \\
\text { mesin haul truck }\end{array}$ & 12 & 83.3 \\
\hline $\begin{array}{l}\text { Mine Loading } \\
\text { Operator }\end{array}$ & $\begin{array}{l}\text { Operator Excavator atau } \\
\text { Shovel untuk pemuatan } \\
\text { batuan ke haul truck }\end{array}$ & $\begin{array}{l}\text { Aktivitas } \\
\text { penambangan, } \\
\text { mesin excavator dan } \\
\text { shovel }\end{array}$ & 12 & 83.3 \\
\hline $\begin{array}{l}\text { Mine } \\
\text { Maintenance }\end{array}$ & $\begin{array}{l}\text { Perbengkelan, perbaikan alat } \\
\text { dan mesin }\end{array}$ & $\begin{array}{l}\text { Peralatan bengkel, } \\
\text { suara alat dan mesin }\end{array}$ & 12 & 83.3 \\
\hline $\begin{array}{l}\text { Mine MWM } \\
\text { Operator }\end{array}$ & $\begin{array}{l}\text { Operator dan perbaikan } \\
\text { pompa air tambang }\end{array}$ & $\begin{array}{l}\text { Aktivitas } \\
\text { penambangan, } \\
\text { pompa }\end{array}$ & 12 & 83.3 \\
\hline $\begin{array}{l}\text { Mine } \\
\text { Maintenance } \\
\text { Service } \\
\text { Equipment }\end{array}$ & $\begin{array}{l}\text { Pengisian bahan bakar dan } \\
\text { oli Haul Truck, pompa, } \\
\text { excavator, dan lainnya }\end{array}$ & $\begin{array}{l}\text { Aktivitas } \\
\text { penambangan, } \\
\text { mesin }\end{array}$ & 12 & 83.3 \\
\hline $\begin{array}{l}\text { Mine Tyre } \\
\text { Fitter }\end{array}$ & $\begin{array}{l}\text { Perbaikan ban Haul Truck } \\
\text { dan Excavator }\end{array}$ & $\begin{array}{l}\text { Aktivitas } \\
\text { perbengkelan, mesin } \\
\text { kendaraan/ alat }\end{array}$ & 12 & 83.3 \\
\hline Mine Welder & $\begin{array}{l}\text { Pengelasan dan perbaikan } \\
\text { dump body }\end{array}$ & $\begin{array}{l}\text { Aktivitas } \\
\text { perbengkelan, alat } \\
\text { gerinda dan las }\end{array}$ & 12 & 83.3 \\
\hline $\begin{array}{l}\text { Mine Road } \\
\text { Maintenance }\end{array}$ & $\begin{array}{l}\text { Pengerasan penyiraman jalan } \\
\text { tambang }\end{array}$ & $\begin{array}{l}\text { Aktivitas } \\
\text { penambangan, } \\
\text { mesin atau alat }\end{array}$ & 12 & 84.04 \\
\hline
\end{tabular}

\section{Pengelompokan pekerja}

berdasar SEG memudahkan penilaian resiko berdasarkan profil paparan yang serupa dalam kelompok aktivitas pekerja. Kelebihan dari metode ini dapat menghindari keharusan penilaian setiap individu sehingga data dari sampel kecil pekerja dapat memprediksi satu kelompok sehingga menghemat sumber daya yang signifikan. SEG dapat digunakan untuk mengumpulkan dan mengklasifikasikan data dan menganalisis tren kesehatan yang dapat dikaitkan dengan sekelompok pekerja sehingga dapat membantu pengusaha menyesuaikan kontrol untuk sekelompok pekerja jika diperlukan (Cai, 2019). Kategori SEG PT. XYZ dilakukan 
dengan pengukuran secara historis paparan, waktu kerja, lokasi kerja, sumber kebisingan, dan menganalisis deskripsi kerja pekerja. Dengan pendekatan terintegrasi didapatkan 12 SEG di area mining PT. XYZ yaitu Mine Batchplant, Mine Blast Crew, Mine Blast Drillers, Mine Drill Sampler, Mine HT Operator, Mine Loading Operator, Mine Maintenance, Mine MWM Operator, Mine Maintenance Service Equipment, Mine Tyre Fitter, Mine Welder, dan Mine Road Maintenance. Penambahan atau pengurangan jumlah SEG disesuaikan dengan perubahan organisasi, aktivitas kerja, hasil observasi dan pengambilan sampel pemeriksaan lingkungan kerja.

\section{Hasil Pengukuran Kebisingan}

Pengukuran paparan kebisingan dilakukan pada masing-masing SEG dengan memasang noise dosimeter Edge5 selama bekerja dengan waktu pemasangan minimal $75 \%$ dari waktu kerja (8 jam). Alat dipasang di pakaian pekerja dekat sumber pendengaran (telinga) sesuai prosedur ACGIH (Association Advancing Occupational And Environmental Health) dan OSHA (Occupational Safety and Health Administration) (Jacobs et al., 2020). NAB untuk waktu kerja 12 jam sesuai Permenaker No.5 Tahun 2018 sebesar 83.3 dB. Dalam 1 tahun, sampel pengukuran kebisingan personal dilakukan minimal 6 kali, dengan hasil sebagai berikut :

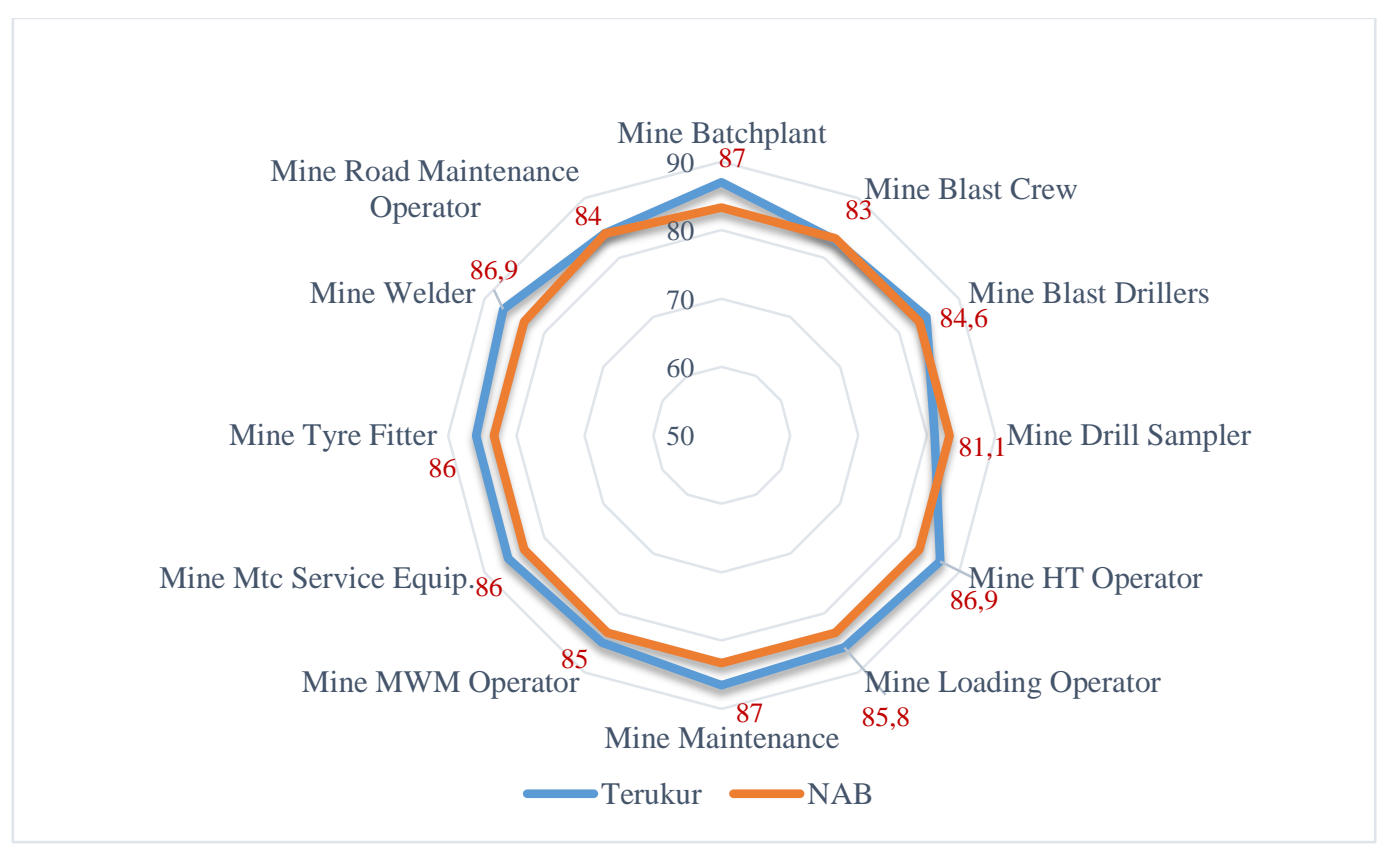

Gambar 2. Hasil Pengukuran Kebisingan Personal Area Mining PT. XYZ 
Hasil pengukuran menunjukkan rata-rata SEG di area mining PT.XYZ berada diatas NAB yang ditetapkan untuk paparan bekerja selama 12 jam yaitu 83,3 dB. Hal ini dikarenakan intensitas suara bising yang berasal dari aktivitas penambangan, perbengkelan, dan alat angkut yang digunakan. Rentang intensitas kebisingan personal pekerja berada pada 81.1 - $87 \mathrm{~dB}$ dengan intensitas tertinggi pada SEG Mine Batch Plant dan terendah di SEG Mine Drill Sampler. Hal ini dikarenakan pada lokasi SEG Mine Batch Plant, kebisingan secara kontinyu berasal dari mesin pemecah batuan atau crusher, sedangkan terendah di SEG Mine Drill Sampler dikarenakan intensitas terhadap kebisingan tidak tetap akibat aktivitas kerja tidak selalu di penambangan. Dari data diatas, beberapa pengendalian terhadap kebisingan dilakukan oleh PT. XYZ salah satunya mewajibkan penggunaan Alat Pelindung Pendengaran (APP) saat bekerja di lokasi dengan intensitas suara yang tinggi.. Selain itu, para operator tidak setiap saat berada disekitar area dengan tingkat paparan kebisingan yang tinggi. Operator hanya akan berada di dekat mesin saat mesin awal dioperasikan ataupun hendak dihentikan. Sehingga, saat mengontrol operasional mesin pun, operator dapat melakukannya melalui ruang operator yang kedap suara.

\section{Usaha Pengendalian Kebisingan}

Usaha pengendalian resiko kebisingan di PT. XYZ dilakukan dengan beberapa pendekatan. Sesuai dengan konsep hirarki control K3, ada 5 teknik pengendalian resiko yaitu eliminasi, substitusi, rekayasa Teknik, administrasi, dan alat pelindung diri. Pengendalian kebisingan secara eliminasi dilakukan dengan memindahkan obyek kerja atau sistem dengan sumber kebisingan. Cara ini dilakukan pada area Mine MWM Operator dengan mengganti sistem monitor pompa menggunakan sistem jarak jauh. Adanya pemasangan CCTV untuk memonitor pompa dan debit air. Secara substitusi, pengendalian resiko dilakukan dengan menggantikan alat, bahan, maupun mesin yang intensitas suaranya tinggi dengan yang lebih rendah kebisingannya. Substitusi dilakukan di beberapa area, seperti SEG Mine Maintenance Service Operator dengan pergantian kendaraan dengan kabin yang lebih kedap suara, termasuk di SEG Mine Drill Operator dan Mine Blast Crew dengan pemilihan alat baru yang tingkat kebisingan lebih rendah.

$$
\text { Pengendalian selanjutnya }
$$

dengan rekayasa Teknik dengan merubah struktur objek kerja dan peralatan untuk mencegah pekerja terpapar potensi bising yang tinggi. Penambahan ruang operator yang kedap suara, penambahan lapisan kedap suara di mesin, dan perawatan 
rutin menjadi cara yang dilakukan PT.

XYZ dalam mengurangi resiko kebisingan pada pekerja. Secara administrasi, PT. XYZ melakukan pengecekan kesehatan rutin kepada para pekerja yang paparan kebisingan tinggi dengan melakukan tes audiometri tahunan dan 6 bulan sekali. Hal ini bertujuan agar diketahui dampak kebisingan area kerja dengan kemampuan telinga menangkap suara, selain itu pengaturan waktu kerja dan waktu istirahat, rotasi kerja untuk mengurangi kelelahan dan kejenuhan dilakukan. Proses training untuk meningkatkan pengetahuan dan kepedulian pekerja terhadap resiko kebisingan dilakukan rutin yang disampaikan oleh tim medis perusahaan. Metode terakhir yaitu penggunaan alat pelindung pendengaran, penyiapan APP diberikan secara gratis kepada pekerja. Jenis APP yang disediakan berupa ear plug dan ear muff. Ear plug terbuat dari apas, spon, dan malam (wax) yang dapat mereduksi paparan kebisingan hingga 26 $\mathrm{dB}$, sedangkan ear muff terdiri dari dua buah tutup telinga yang dapat merduksi intensitas suara hingga $30 \mathrm{~dB}(\mathrm{~A})$ dan sekaligus melindungi bagian luar telinga dari benturan benda keras atau percikan bahan kimia.

\section{KESIMPULAN}

Sumber kebisingan di area mining PT.XYZ berasal dari aktivitas penambangan, peledakan, alat, dan mesin yang mengakibatkan intensitas yang cukup tinggi di masing-masing SEG. Pembagian SEG dilakukan berdasarkan pengelompokan pekerja sesuai resiko kerja, paparan kebisingan, jam kerja, dan sumber kebisingan yang sama dalam satu kelompok. Ada12 SEG di area mining PT. XYZ yaitu Mine Batchplant, Mine Blast Crew, Mine Blast Drillers, Mine Drill Sampler, Mine HT Operator, Mine Loading Operator, Mine Maintenance, Mine MWM Operator, Mine Maintenance Service Equipment, Mine Tyre Fitter, Mine Welder, dan Mine Road Maintenance. Hasil pengukuran kebisingan personal menunjukkan rentang 81.1-87 dB dengan SEG tertinggi di area Mine Batch Plant dan terendah di SEG Mine Drill Sampler. PT. XYZ telah melakukan upaya pengendalian kebisingan dengan prinsip hirarki kontrol yaitu eliminasi, substitusi, rekayasa teknik, administrasi, dan alat pelindung diri. Saran untuk PT. XYZ agar melakukan pemeriksaan dampak kebisingan pekerja melalui tes audiometri, penggunaan Alat Pelindung Telinga (APT) secara konsisten sesuai identifikasi resiko kebisingan di tempat kerja sehingga dapat melindungi pekerja 
dari penyakit akibat kerja akibat

kebisingan.

\section{REFERENSI}

Amir, J. et al. (2019) Hubungan Kebisingan, Kelelahan Kerja Dan Beban Kerja Mental Terhadap Stres Kerja Pada Pekerja Bagian Body Rangka PT. X, Jurnal Kesehatan Masyarakat (Undip). Fakultas Kesehatan Masyarakat Universitas Diponegoro. Available at: http://ejournal3.undip.ac.id/inde x.php/jkm (Accessed: 5 April 2021).

Beamer, B. (2016) 'Noise Control Engineering Strategies'. OnePetro.

Bonnet, F. et al. (2019) 'In-ear noise dosimetry under earplug: Method to exclude wearerinduced disturbances', International Journal of Industrial Ergonomics, 74, p. 102862. doi: 10.1016/j.ergon.2019.102862.

Cai, Y. (2019) 'Occupational Safety in China's Coal Mining Industry: The Roles of Regulations, Human Resources, and Labor Relations', in, pp. 119-152. doi: $10.1108 / \mathrm{s} 0742$ 618620190000025008.

ESDM, K. M. (2018) Peraturan Menteri ESDM No. 26 Tahun 2018 tentang Pelaksanaan Kaidah Pertambangan yang Baik dan Pengawasan Pertambangan Mineral dan Batubara.

Fitriana, H. M. R. (2009) 'Identifikasi bahaya dan penilaian resiko kebisingan pada proses operation di area grinding PT. Newmont Nusa Tenggara'. Available at: https://digilib.uns.ac.id/dokume n/9850/Identifikasi-bahaya-danpenilaian-resiko-kebisinganpada-proses-operation-di-areagrinding-PT-Newmont-Nusa-
Tenggara (Accessed: 5 April 2021).

Hadzi-Nikolova, M., Mirakovski, D. and Doneva, N. (2016) 'Noise Induced Hearing Loss (NIHL) in mining'.

Haryandi, Setiawati, V. R. and Mayasisca (2020) 'Implementasi Hearing Conservation Program Industri Pertambangan Sebagai Upaya Pencegahan Penyakit Akibat Kerja (Pak) Akibat Resiko Kebisingan; Studi Kasis Di Area Grinding, Process Plant di PT. ABC, Sumbawa Barat, Nusa Tenggara BaraT', Hexagon Jurnal Teknik dan Sains , 1(2), pp. 1-8. Available at: https://jurnal.uts.ac.id/index.php /hexagon/article/view/611 (Accessed: 5 April 2021).

Jacobs, N. et al. (2020) 'Noise exposures in different community settings measured by traditional dosimeter and smartphone app', Applied Acoustics, 167, p. $107408 . \quad$ doi: 10.1016/j.apacoust.2020.107408

Kemenaker (2018) Peraturan Menteri Tenaga Kerja No. 5 Tahun 2018 tentang Keselamatan dan Kesehatan Kerja Lingkungan Kerja.

Keputusan Dirjen Minerba, E. (2019) Kepdirjen Minerba No.185.K/37.04/DJB/2019

tentang Petunjuk Teknis Pelaksanaan Keselamatan Pertambangan dan Pelaksanaan, Penilaian dan Pelaporan Sistem Manajemen Keselamatan Pertambangan Mineral dan Batubara.

Mayasari, D. and Khairunnisa, R. (no date) Pencegahan Noise Induced Hearing Loss pada Pekerja Akibat Kebisingan Prevention of 
Noise Induced Hearing Loss on Workers Due to Noise Expossure.

Mcbride, D. I. (2004) 'IN-DEPTH REVIEW Noise-induced hearing loss and hearing conservation in mining'. doi: 10.1093/occmed/kqh075.

Octavia, A., Asnawati, A. and Yasmina, A. (2013) 'Pengaruh Intensitas Kebisingan Lingkungan Kerja Terhadap Waktu Reaksi Karyawan PT. PLN (Persero) Sektor Barito PLTD Trisakti Banjarmasin', Berkala Kedokteran, 9(2), pp. 181-189. Available at: https://ppjp.ulm.ac.id/journal/in dex.php/jbk/article/view/948 (Accessed: 7 December 2020).

Utami, N. T., Nirmala, A. and Meilasari, F. (2020) KAJIAN DAMPAK KEBISINGAN AKIBAT AKTIVITAS PERTAMBANGAN

GRANODIORIT PADA PT GILGAL BATU ALAM LESTARI KABUPATEN MEMPAWAH KALIMANTAN BARAT, JeLAST : Jurnal PWK, Laut, Sipil, Tambang. Available at:

https://jurnal.untan.ac.id/index.p hp/JMHMS/article/view/40309 (Accessed: 26 March 2021). 